\title{
An Evaluation of the CAST Program using a Conceptual Model of School-based Implementation
}

\author{
Denise Corboy \\ University of Ballarat \\ Dr. John McDonald \\ University of Ballarat
}

Denise Corboy (nominated author)

Centre for Health Research and Practice

University of Ballarat

PO Box 663

Ballarat. Vic. 3353

PH: 03. 53279516

E: d.corboy@ballarat.edu.au

Dr. John McDonald

Centre for Health Research and Practice

University of Ballarat

PO Box 663

Ballarat. Vic. 3353

PH: 03. 53279818

j.mcdonald@ballarat.edu.au 


\begin{abstract}
Therapeutic prevention and/or early intervention programs for children at risk of developing disruptive behaviour disorders are increasingly being implemented in schools. One such Australian school-based program is CAST (CAMHS (Child and Adolescent Mental Health Service) and Schools Together), an evidenced-based program treating children with emerging disruptive behaviour disorders in the early primary school years. The current evaluation examines the process of implementation of the CAST program in primary schools. By using a conceptual model of school-based implementation (developed by Greenberg, Domitrovich, Graczyk \& Zins, 2005) the wide array of factors that can affect successful implementation at the school level were identified, and those elements critical to implementation quality were examined. Semi-structured individual and group interviews were conducted with a sample of 69 school personnel across 16 schools in the City of Ballarat and wider Grampians region of Victoria, in both government and Catholic primary schools. Results showed that schools were highly satisfied with the quality of CAST resources and personnel, and the implementation and delivery of sessions as planned. Aspects that impacted negatively on the implementation process were the lack of parental engagement; the lack of classroom follow-up in some schools; the level of readiness and pre-planning by the schools; and the availability of technical support. Greenberg's conceptual model appears to be a robust and useful framework to utilise in examining the implementation of the CAST model, as it allowed close examination of how the program was implemented within naturally occurring constraints. It allowed the identification of elements within the CAST model and the associated support system that must be maintained and nurtured by the collaborating parties, in addition to the factors at a school level that are potential barriers to effective implementation. Identification and examination of such factors assist in ensuring quality outcomes for school-based interventions in the future.
\end{abstract}

Key Words: program evaluation; implementation quality; school-based mental health; disruptive behaviours 


\section{Introduction}

The most recent research into the prevalence of mental health disorders in Australian children and young people has indicated that $14 \%$, or approximately 500,000 children and adolescents have significant mental health problems (Sawyer, Arney, Baghurst et al., 2001). More specifically, it identified that delinquent behaviour (7\%); attention problems (6.1\%); and aggression (5.2\%) are major mental health problems for Australian children. Three percent of children met the diagnostic criteria for Conduct Disorder - the most severe behavioural disorder in childhood and adolescence (Hill, 2002). Disruptive behaviour disorders (including Conduct Disorder and Oppositional Defiant Disorder) are disorders of social and psychological development, thought to be caused by interactions between biological, psychological and social factors. Over the past decade therapeutic treatments for disruptive behaviour disorders have moved toward identification of children 'at risk' during early childhood. The aim of early identification is to select these children for therapeutic prevention or early intervention programs during the formative years. There is strong evidence showing that if left until the teenage years disruptive behaviour disorders can be highly resistant to treatment. Furthermore, several promising programs begun in preschool and early primary school have demonstrated their capacity to enhance the wellbeing of 'at risk' children (for review see Greenberg, Domitrovich, \& Bumbarger, 2001; Sanders, 1999). School-based programs for both children 'at risk' and their families have proven effective in achieving such outcomes as: engaging families in the school community; improving the academic attainment of students; decreasing rates of absenteeism; and decreasing anti-social and disruptive behaviour in the classroom (Scott-Skillman, 1992; Sutherland \& Sokal, 2003). There has been a recent history of success of such school-based interventions. For example, in the United States, the Families and Schools Together program (FAST Track), is a multi-component, intensive intervention for children with early-onset conduct problems. Evaluations of this program have indicated program success, in that Fast 
Track has continued to influence certain key areas of children's adjustment throughout the elementary school years, decreasing children's likelihood of presenting with problems in their social, peer, or home functioning (Bierman et al., 2004). Similarly, the Linking the Interests of Families and Teachers (LIFT) program has to date had a positive impact. This prevention program was designed for delivery to children and parents within the elementary school setting, and targets for change those child and parent behaviours thought to be most relevant to the development of adolescent delinquent and violent behaviours, namely child oppositional, defiant, and socially inept behaviour and parent discipline and monitoring. During the 3 years following the program, the LIFT delayed the time that participants first became involved with antisocial peers during middle school, as well as the time to first patterned alcohol use, to first marijuana use, and to first police arrest (Eddy, Reid \& Fetrow, 2000).

One such Australian school-based program is CAST (CAMHS (Child and Adolescent Mental Health Service) and Schools Together). Began as a three year pilot project, CAST is aimed at the prevention, early identification, and treatment of emerging or present Conduct Disorder and Oppositional Defiant Disorder (Disruptive Behaviour Disorders) in grades Prep, Year 1, and Year 2. The project is a collaborative endeavour between Grampians Region CAMHS and the Department of Education and Training, Central Highlands/Wimmera Region of Victoria, and the Catholic Education Office, Ballarat. The project was initiated and funded by the Mental Health Branch of the Department of Human Services for a three year period, in two regions of Victoria (Eastern Melbourne and Grampians). The project employs evidence-based early intervention and treatment methods, and takes a multi-faceted approach: (1) child-focused interventions utilising a group-based approach; (2) parenting interventions; (3) school-based interventions with a focus on professional development for school staff; and (4) development of referral 
pathways/protocols for individual intervention. The CAST project includes the following key components:

- An initial package of training and education to raise awareness and educate about emerging and/or present Conduct Disorder for all Primary School teachers in the region, with more specific education as the pilot continues and high prevalence clusters are identified.

- Provision of class room strategies with an emphasis on problem solving, social restitution, and other social skills building experiences that can be integrated into classroom interactions.

- Professional mentorship for staff in school identified as pilot schools, spread out across the life of the project.

- Screening at the class level of all children in Prep, Year 1, and Year 2 to identify those children with absent, mild, moderate or severe disturbances of conduct and emotions.

- The mild/moderate and severe groups will be provided with more specialised educational, psychological and psychiatric assessment, a function of the project team.

- Parent management training in school settings for the parent(s)/carer(s) of those children identified with mild/moderate and severe disturbance of conduct and emotions.

- Coping, anger management, and social skills groups in schools for those children with moderate levels of disturbance.

- Home based family support work for parent(s)/carer(s) of those children with severe levels of disturbance.

- Referral to CAMHS therapists for comprehensive child psychiatric assessment for those children in the severe group 
CAST program funded in recognition of the need to:

\section{CONTEXT OF CAST SERVICE MODEL}

- Improve the capacity of schools and parents to respond to children with disruptive behaviours

- Strengthen partnership between CAMHS and schools

- Improve the symptomatology and functioning of children with disruptive behaviours

\section{Children \& ParentsSchools}

\section{CONTEXT OF CAST EVALUATION}

- Characteristics and needs of children and parents - Knowledge across schools and community

- Prevalence of disruptive behaviours- Collaboration and partnership between agencies

- Referral pathways between schools and agencies

\section{CAST Inputs (Activities):}

\section{Children \& Parents}

\section{SERVICE MODEL}

- Universal in-class social skills and peer interaction program

- Weekly group for selected children

- Weekly parent group

- Individual work with children and/or families

- Secondary consultations

- Referral to support agencies

\section{EVALUATION}

- Acceptability of program content

- Acceptability of methods

\section{Schools}

\section{SERVICE MODEL}

- Teacher Education on behaviour disorders and behaviour management

- $\quad$ Screening by teachers of all children (Prep2)

- Teacher implemented in-class activities

\section{EVALUATION}

- Acceptability of program content

- Acceptability of methods

\section{Process of CAST:}

\section{Children \& Parents}

SERVICE MODEL

- Parents provide permission for children to be screened

- Parents of selected children complete measures of child behaviour and parental functioning

- $\quad$ Parents and children attend weekly group sessions

- Parents and children receive individual support where necessary

\section{EVALUATION}

- Parental engagement

- Parental participation

- Take-up rate

- Dropout rate during program

\section{$\underline{\text { Schools }}$}

\section{SERVICE MODEL}

- Teachers attend education \& info sessions on CAST

- Teachers complete screening - discuss participant selection with CAST clinician

- School staff co-facilitate children and parent groups

- Teachers deliver in-class activities

\section{EVALUATION}

- Skill development

- Staff practices

- Adherence to program

- Integrity of intervention

\section{Products (Outcomes) of CAST:}

\section{Children \& Parents}

\section{SERVICE MODEL}

- Improved symptomatology and functioning of children (behaviour change)

- Improved parent functioning (psychosocial wellbeing, parental competence and satisfaction)

- Improved parenting knowledge and skill (implementation of parenting strategies)

\section{EVALUATION}

- Child outcomes (behaviour change)

- Parent functioning (psychosocial wellbeing, parental competence and satisfaction)

- Parenting knowledge and skill (implementation of parenting strategies)

\section{$\underline{\text { Schools }}$}

\section{SERVICE MODEL}

- Improved capacity of teachers to respond early and effectively to disruptive behaviours

- Strengthening of partnership between school communities, students support services staff and CAMHS

- Under a train the trainer model, schools continue to run the program

\section{EVALUATION}

- School personnel's efficacy, perception, and satisfaction with program

- In-school support of program

- Collaborative relationships

- Significance to schools

- Future innovation or adaptation

- Sustainability 
The above description of the CAST service model and evaluation framework follows the CIPP (Context Input Process Product) model (Stufflebeam, 2000), and has been adapted from an evaluation developed for the CAST program (L. Hayes, personal communication, February 28, 2007). The shaded boxes in Figure 1. indicate the scope of the current qualitative evaluation. While this evaluation focussed on the implementation of the program from the schools' perspective, an evaluation was being conducted in parallel which looked at the outcomes for parents and children. Results of this evaluation will be published in a soon to be released report commissioned by the Mental Health Branch of the Department of Human Services. The initial success of the CAST pilot program has been capitalised on with the announcement in July 2006 that the program had received recurrent funding. CAST is currently being rolled out in primary schools across Victoria.

School-based programs have been rigorously evaluated by the international scientific community, particularly in the United States, where a systematic approach to evaluation of program models involves efficacy trials (formal evaluation using a randomised clinical trial); effectiveness trials (evaluation of empirically supported programs in real world settings); and "going to scale" (proven programs are broadly disseminated). A consequence of the move towards dissemination of evidence-based programs is that more focus is being directed to understanding the complexities of program implementation (Domitrovitch \& Greenberg, 2000; Elias, Zins, Graczyck, \& Weissberg, 2003), with a growing acknowledgement that even the most proven interventions are dependent upon constraints of the environment in which they are embedded (CASEL, 2003). However, our search of the published, peer reviewed Australian literature revealed very few reports on process, impact or outcome evaluations of the implementation of school-based interventions. Moreover, those that have been published typically do not appear to utilise evaluation frameworks or models; this, then, limits the capacity 
for cumulative knowledge to be built about the implementation or effectiveness of programs.

The current evaluation examines the process of implementation of the CAST program in primary schools. By using a conceptual model of school-based implementation (developed by Greenberg, Domitrovich, Graczyk \& Zins, 2005) the wide array of factors that can affect successful implementation at the school level are identified, and those elements that are critical to implementation quality are examined.

\section{Method}

The authors were commissioned by the Department of Human Services (Mental Health Branch of Victoria) to undertake an external process evaluation of the CAST project. Prior to the commencement of the evaluation, approval to conduct the study was obtained from the University of Ballarat Human Research Ethics Committee. The process evaluation focussed on the implementation of the project and the establishment of collaborative relationships, with the overall objective being to provide feedback on the process of implementation, to refine the service model, and to make recommendations regarding the transferability and sustainability of the program. The findings from the evaluation were presented to schools and agencies in the form of individual and combined reports.

\section{Participants}

Semi-structured individual and group interviews were conducted with a sample of 69 school personnel across 16 schools in the City of Ballarat and wider Grampians region of Victoria, in both government and Catholic primary schools. Schools that ran the CAST program in Terms 1 and 2 of 2005, and Term 1 of 2006 were approached to participate in the evaluation. All schools approached agreed to participate.

\section{Procedure}

The interviews were conducted, in the majority of cases, during the school term following the implementation of the CAST program. The researcher requested that the school make available 
for interview all staff involved in the CAST program. Personnel interviewed included school principals, assistant principals, primary welfare officers, student wellbeing co-ordinators, and Prep to Grade 2 (P-2) teachers. Interviews were conducted individually with all school principals. In the majority of schools, welfare personnel were interviewed individually, except where there was more than one member of staff on the welfare team. Assistant principals were interviewed individually or in conjunction with welfare staff. When there was more than one P-2 teacher available for interview, a group interview was conducted. All interviews were conducted during 2005/6, during or after school hours, depending on staff availability. Interviews were conducted face-to-face or via telephone, and the interviews lasted 20-50 minutes. Hand-written notes were used to record participants' responses to questions relating to the following broad topics: the CAST service model; project implementation; collaborative relationships; and transferability and sustainability.

Analysis

For the purposes of this paper, interview data were analysed using the Conceptual Model of School Based Implementation (Greenberg, Domitrovich, Graczyk \& Zins, 2005), which is a theory-driven model for studying the implementation of programs in school-based settings. The model was designed to evaluate those school-based programs that have undergone efficacy and effectiveness trials to become "model programs", and have consequently "gone to scale”. CAST differs from these programs in that it uses existing evidenced-based programs (the Signposts program which has undergone effectiveness trials, and the Child Group program which has undergone efficacy trials), in conjunction with newly developed interventions modified and refined throughout the course of implementation. Despite these differences, the implementation issues appear to be the same for the most part, making the use of the Greenberg model warranted. In addition, Greenberg and colleagues (2005) state that the model can be used by program developers to assess and improve the quality of their program and training system. 
While the model is limited in that it does not sufficiently attend to the partnerships that underpin successful implementation of school-based preventive programs, which will be discussed later, its utility is in its explication of interrelated factors, present in school settings, which are critical to the effective implementation of school-based programs.

The Conceptual Model of School Based Implementation differentiates between explaining program outcomes and describing how a program should be implemented to reach intended outcomes. It addresses how evaluation can be based on measures of actual program delivery, as well as measures of the support system for training and consultation. According to this model, the definition of implementation quality is based on the discrepancy between the intervention as planned and the intervention as delivered, and the discrepancy between the implementation support as planned and the implementation support as delivered. Four dimensions of a planned intervention can be evaluated - program model, quality of delivery, target audience, and participant responsiveness. The aspects of implementation support that can be evaluated are pre-planning, quality of materials, technical support materials, quality of technical support, and implementer readiness. The following analysis addresses each of these dimensions in order to determine whether any discrepancies were evident between the CAST model as planned and the CAST model as delivered.

\section{Results}

\section{A. Planned intervention}

\section{Program model}

The CAST program model requires each school to provide an in-school co-facilitator to work in conjunction with a CAST clinician in co-ordinating the program and delivering weekly 90 minute sessions to a group of up to eight targeted children for one school term. Weekly parent sessions are also conducted at the school by CAST personnel and where possible an in-school co-facilitator. In addition, the model requires that teachers complete a pre- and post- child 
behaviour survey for each child in their class, and conduct follow-up activities in the classroom throughout the program.

The extent to which this model was implemented varied from one school to the next, although the majority of schools reported that program requirements were adhered to by both school staff and CAST personnel. Twelve of the 16 schools reported that implementation of the program occurred in line with action plans (“CAST personnel were A1 in terms of punctuality and following timelines"; "we were always informed by CAST workers of any changes”; "CAST personnel accommodated the school in terms of times and dates”). The reasons for disruption to the implementation schedule at the remaining four schools included interruption from other school programs, difficulties due to running the program over two terms, and a re-negotiated start time and date.

Teachers at all schools completed the child behaviour surveys for all students in their classes. They used their existing time release to complete the surveys, and although it was reported to be a valuable and accurate exercise, personnel from eight schools expressed concern that the process caused an extra workload for teachers, and suggested extra time release for teachers to complete this screening process.

At all schools the children's groups and parent groups were run on a weekly basis. However, the incorporation of follow-up activities in the classroom varied from school to school, from teacher to teacher, and even within individual classrooms with teachers reporting that some weeks the activities were missed due to timing or scheduling constraints. While the majority of teachers reported that class lessons ran in conjunction with group activities as scheduled, staff at nine schools reported that some teachers did not always conduct the activities; "probably didn't use 
them to their full potential" or "did them to the best of our ability... some required a lot of work from the teachers, or were not achievable due to lack of space”.

\section{Quality of delivery}

All schools indicated that the program delivery by the CAST personnel was of high quality. The CAST clinicians were, for the most part, described in very glowing terms ("very positive, consistent, organised and had a great rapport with the kids”, "ability to adapt and accommodate... dedication and commitment"; "professionalism, knowledge and friendliness"; “an accessible resource”).

\section{Target audience}

Children were selected for inclusion in the CAST program based on the results of the child behaviour surveys, and round table discussions between CAST clinicians and school staff to negotiate and confirm selections. Although attendance was not documented by the schools (this data was collected by the CAST clinicians), all schools reported that the attendance rate at the children's groups was high, as children "looked forward to" and "felt privileged to be involved"

in the CAST sessions. In terms of whether the CAST model is targeting the right students, opinion among the schools was divided. Teachers at all schools agreed that the children selected for inclusion in the CAST program were appropriately targeted in terms of their behaviour, but there were concerns expressed about the age-appropriateness of some elements of the program. While school staff acknowledged the importance of early intervention, at seven schools there was concern expressed about the range of ages in the children's group, particularly the inclusion of children in their first year of school, who were reported in some cases to be lacking in maturity, reading skills, and the ability to contribute to group discussions. 
Attendance rates for the parent groups were not as high. All schools reported some difficulty in engaging the parents of the CAST participants. While the schools did not keep records of parental attendance (this information was collected by the CAST clinicians), an estimated participation rate of around 30\% was commonly reported by the schools ("same old parents didn't engage - only 2-3 regulars”; "three out of eight parents turned up consistently”; “those targeted by CAST are the ones who generally don't engage at all”). All schools reported that they tried to be "open and accessible” to parents, offering evening sessions, childcare, the option of bringing toddlers to parent groups, in-home sessions, or just maintaining phone contact. Many of these offers were reportedly not taken up by parents. Whether to expend more energy and resources in engaging parents was a point of difference among the schools. Two schools suggested that trying to engage parents is a waste of time, and it is more beneficial to focus on the students. Most schools, however, considered offering better outreach to parents, including more childminding options, alternative meeting times, and trying to establish a stronger relationship between school staff and parents. At four schools, the CAST parent intervention became more universal than targeted, with other parents in the school community expressing interest in the groups, and becoming regular attendees.

\section{Participant Responsiveness}

The "acceptability" of the intervention was rated as high. According to Greenberg and colleagues (2005), participants who are accepting of a program (that is, they like the program and are actively engaged in it) are more likely to benefit from the intervention. In all schools the CAST sessions were reported to be received extremely well by the children involved (“children enjoyed going, especially the rewards and the end party"; "they felt excited and important, and any positive response from these children is good"). Furthermore, all schools indicated that the children benefited in some way from attending the groups, from being able to "work together 
and feel equal" to "having the opportunity to model behaviour, and become leaders in small groups - opportunities usually denied them in a classroom setting”.

The removal of CAST participants from the classroom was well received by teachers. Seven schools reported that the quality of the teaching time in the classroom improved when the children involved in the program left the room, due to the improved environment ("It made the teachers realise how much time and energy these children normally take up"; "it benefited the other children to have the 'prime movers' out of the room”; "peaceful classrooms!”). Two schools reported that removing children from the classroom was disruptive, but it was generally reported that because it is not unusual for children to be removed from classrooms, individually or as a group (for Reading Recovery or music lessons for example), the removal of the CAST participants was easily accommodated by both teachers and fellow students.

Acceptability of the program by teachers was generally high, particularly in regard to the CAST resources, personnel, screening process and professional development. Acceptability among teachers as reflected in the implementation of classroom activities was however more widely varied. These issues will be more fully discussed in the following sections.

While the acceptability of the program among parents was not able to be directly addressed (no interviews were conducted with parents for this evaluation), teachers variously reported that parents gave positive feedback to school staff about their involvement in CAST - "parents appreciated the support” and the "opportunity to pour their hearts out to an independent professional”.

Acceptability of the program was also high among school principals. All principals interviewed expressed their commitment to the CAST program, indicating that the model offered a holistic 
approach to address currents needs in their school, and at the same time facilitating much needed support from external professionals.

\section{B. Planned implementation support system}

\section{Pre-planning}

According to Greenberg and colleagues (2005) pre-planning refers to any preparation made by the school before implementation of a new program. It can include factors like capacity, awareness, commitment, and incentive for change. The schools involved in the pilot program were required to register an expression of interest in implementing the program, and this reflects an acknowledgement of a need for change in the school. The decision to participate in the CAST program was made by the school principal, with the degree of consultation with staff varying from school to school. In two schools the CAST program was introduced as an initiative of the Primary Welfare Officer. Many of the schools involved regarded themselves as "high need", and reported the "presence of a number of students in the P/1(Prep/Grade 1) area with challenging behaviours" and "social deficits". This was expressed most particularly by welfare staff. The nine school principals interviewed reported being committed to the program, even if not directly involved in implementing it. Interviews with teachers generally revealed an awareness and acceptance of the CAST program. There were however, individual teachers at eleven schools who either had negative initial expectations of the program - "a lot of work for short term gains”; “just another new thing”, or reported being under-prepared for their role in implementing the program - "teacher booklet was not explained or distributed to all”; "(classroom follow-up) not a facet that to my mind was part of the program”.

In terms of school readiness to implement the program, only four schools reported difficulty in resolving venue or scheduling issues. One of these schools reported many obstacles to implementation, most of which were related to in-school issues, such as poor in-school 
communication, lack of a suitable venue, staffing problems, lack of follow up in the classroom, program re-scheduling, and poor communication between school staff and CAST.

\section{Quality of materials}

Greenberg and colleagues (2005) state that successful program implementation is more likely when the program materials are user friendly, visually appealing, age appropriate, and culturally sensitive. Without exception, schools praised the quality and content of CAST resources. One staff member reported that the parent newsletter and DVDs were "like a self-help support package” for parents. The classroom booklets were generally reported as user-friendly and of high quality.

\section{Quality and availability of technical support}

Technical support refers to the structure, content and timing of any pre-intervention training, as well as ongoing support during the delivery of the program. Although an initial package of training and education to raise awareness and educate about emerging and/or present Conduct Disorder was designed and presented to primary school teachers in the region, the concept of professional development (PD) presented to each pilot school was not initially a part of the CAST service model. It was assumed that teachers had a shared knowledge of challenging behaviours, and the CAST team reported that they were very conscious of not coming into a school and telling teachers how to do their jobs. After the first round of implementation in schools, it became clear that CAST needed to inform the schools more about their clinical approach and how it differed to the traditional teaching approach. Professional development sessions were consequently conducted by CAST personnel at all schools. A Staff Wellbeing workshop was also conducted by Ballarat Health Services (BHS) and Department of Education and Training (DE\&T), which was particularly well received by the schools as a validation of the "stress involved in dealing with challenging behaviours every day". School staff reported that 
the sessions were positive, informative, and relevant to the whole school ("brief and very structured - but with lots of room for discussion"; "it encouraged new thinking as well as reinforced existing knowledge”; "it was presented in a practical way, emphasising sense of humour and a positive attitude”).

The majority of school staff members indicated that more professional development would be of benefit. Three schools specified that a training session on running the parent groups would be of benefit, two indicated they would benefit from a training session on administering and scoring the screening tool, and another suggested professional development on implementing CAST activities in the classroom.

Many schools reported that the CAST clinicians provided extra support in the form of secondary consultations. In eleven schools, staff reported that CAST personnel were available for support and advice in dealing with children outside of the program, in addition to assistance with CAST children who required further intervention. This support included assistance in further assessment, securing special funding, or simply offering ideas and strategies to teachers in dealing with other children in their classrooms.

The need for extra support for school staff in terms of time release was rated as important by more than half the schools, particularly for the co-facilitators, who in most cases used their existing time release to co-ordinate and run the program. In terms of ongoing support throughout the program, schools reported that the support given by the CAST clinician was valuable (“... made herself available for teachers over lunchtimes in the staffroom, and met with them weekly to discuss the program and the children”; “good feedback was given - teachers were filled in”). At the majority of schools, however, the teachers expressed a need for more support, particularly scheduling more avenues of communication/feedback into the program. They expressed a desire 
to receive more feedback, formally or informally, and to be more involved in the process, either by sitting in on the children's groups, or having the CAST clinician sit in on their classroom to get feedback on their own performance ("we need more dialogue about the children's progress, as well as our own progress in the classroom"; "even a note on the staff noticeboard”). Staff at ten schools indicated the need to formalise a process whereby co-facilitator, teacher, parents and CAST clinician meet, in a fashion similar to the initial parent/teacher interview, but to discuss issues and progress.

Continuing support for implementers (school based co-facilitators and teachers) once the initial program concludes was a concern for most schools. While the focus of the program was on capacity building, in training the in-school facilitator to a level where they felt competent enough to run the program with limited external support, fourteen schools reported that the sustainability of the program was highly dependent upon ongoing support from a CAST clinician. They indicated that support would be required to assist in running the parent groups, to run further professional development sessions, or simply in the form of a mentor or a "go-to person" for advice and support. All schools indicated that they would be interested in continuing to run the CAST program in some form in the future, and many saw the need for the collaboration between CAMHS and the schools to continue. Furthermore, there was a reported improvement in the quality of the relationship between the schools and CAMHS as a result of the CAST program. Twelve schools reported that they were now more comfortable in calling CAMHS directly, were more aware of the services offered, or were simply pleased at the opportunity to establish an ongoing and improved relationship.

\section{Implementer readiness}

All school personnel were asked about their initial expectations of the program. Staff at most schools expressed positive expectations and a belief in their ability to implement the CAST 
program. All co-facilitators expressed confidence in delivering the program to the children's groups, and felt well supported in this by the CAST clinician. Seven co-facilitators reported, however, that they were initially unsure of their role in the children's groups, particularly in regard to discipline, and enforcing the school’s code of conduct. (“Group management was difficult for a non-teacher"; "Discipline needs to be enforced at the outset, as children get the wrong message about what is acceptable behaviour in the school”).

\section{Discussion}

Greenberg's model has proven to be useful in reducing the results into two major conclusions that we now discuss. Analysis of the qualitative interview data revealed that, first, the CAST program was clearly well received, and many aspects of the program were well implemented at the majority of schools; and second, there were some discrepancies between the implementation of the intervention and the related support system as planned, and that which was actually delivered. It is important to acknowledge that as a pilot program, there would inevitably be modifications and further developments to the CAST model. However, it is nonetheless useful to examine the areas where outcomes did not meet expectations.

Aspects of implementation with which schools were satisfied included the quality of CAST resources and personnel; the delivery of sessions as planned; and the schools' acceptability of the program. A clear majority of schools reported that the program was delivered in line with action plans, at times and in venues that were successfully negotiated between school staff and CAST personnel before the program started. School principals indicated that they saw the program as a priority. It was therefore incorporated into the curriculum with relative ease. The support and leadership of the school principal is of central importance to school-based implementation. Fullan, Miles and Taylor (1980) found that principal leadership impacted all aspects of the 
implementation process from entry through to maintenance of innovation. Furthermore, Kam, Greenberg, and Walls (2003) found that higher levels of principal support significantly improved implementation and subsequent outcomes such as behavioural problems and emotional competence. In concordance with this, the findings of the present study indicate that the CAST program was implemented most effectively in those schools that operated under the strong leadership of a committed school principal or assistant principal. It was also evident that the full commitment of the in-school co-facilitator was critical. All co-facilitators interviewed described the program in a positive light, understood the model's theory, and had high expectations of benefits for students. These factors have been shown to influence the motivation to implement a school-based program (Reimers, Wacker, \& Koeppl, 1990; Kealey, Peterson, Gaul, \& Dinh, 2000; Clark \& Elliot, 1988). Furthermore, the co-facilitators showed a depth of commitment in taking on the extra workload involved in delivering the program, in the belief that it would be effective. Even at schools where aspects of the implementation failed to go to plan, the cofacilitators remained convinced of the potential of the program.

Greenberg's model has been particularly useful in pinpointing aspects of the implementation process that did not go to plan. First, the lack of parental engagement and the lack of classroom follow-up in some schools meant that the program's target audience was not always reached. Second, the readiness and pre-planning of the schools was shown to be important to the effectiveness of the program. The third dimension that influenced quality implementation was related to the availability of technical support. This factor has implications for program sustainability in terms of how well the program is institutionalised within each school once the CAST clinician's role at that school has concluded, and also in regard to how well the school is supported by the collaborating agencies, in continuing to deliver the program. 
Greenberg and colleagues (2005) note that even when personnel deliver a program faithfully, if targeted participants are absent then the effectiveness of the intervention is compromised. An important dimension of the CAST model lies in working with parents and carers of the targeted and indicated children. Involving parents in the CAST program was a challenge for most schools. The $30 \%$ participation rate estimated is in line with other research on parenting groups, which report participation rates of around 25 to 30\% (Spoth, Goldberg, \& Redmond, 1999; Stormshak, Kaminski, \& Goodman, 2002). Schools reported a variety of understandable problems (for example, transportation, childcare, stigma) that prevented families from attending groups, and the vast majority of schools reported that they, and the CAST clinicians, made concerted efforts to engage targeted parents, often to no avail. The majority of schools indicated that achieving parental involvement in any program is an ongoing challenge ("selective support (of school activities) was common and difficult to overcome"; "there is a lack of motivationthey are low SES (socio-economic status), many have had negative experiences at school themselves, so they are very difficult to engage”). Furthermore, some school personnel believed that work commitments made it difficult for some parents to attend, while another described some of their parents as having a "you fix it" mentality. This coupled with "the notion that their ability was being questioned, and blame was being assigned”, meant that some parents were reluctant to become involved. School staff reported that parents who did attend often failed to complete home tasks. Despite this, teachers indicated that the parents involved were generally positive about CAST, one school reporting that their parents were relieved to have been offered some help, and that working in groups “allowed them to see that they weren't alone in dealing with challenging children.” The majority of schools indicated that the inclusion of parents in the program was worthwhile, and would in future consider different approaches to engage them. Stormshak, Dishion, Light and Yasui (2005) found that using diverse modes of communication (particularly brief, supportive contacts in the form of phone and email contacts) may be one way to work with families in the context of schools. 
A further implementation issue relating to the program reaching its target audience was the lack of follow-up by teachers in the classroom. One of the aims of the CAST program is to encourage the implementation in the classroom of activities that complement the children's group sessions. This is designed to reinforce the strategies and maintain the skills learned in the children’s groups, in addition to providing a more universal intervention for all children in Prep to Grade Two. Classroom activity booklets for use by teachers were provided as part of the overall CAST resource package. At many schools the extent to which the classroom activities were implemented was shown to be dependent upon two factors. First, those teachers who had more than one CAST student in their class were more likely to implement the activities. Second, follow-up in the classroom was related to how well the junior teachers accepted and understood their role in the program. The reasons for this are discussed more fully in the following section.

Pre-planning is any preparation made by the school before the implementation of an identified intervention (Greenberg et al., 2005). For the purpose of this paper we will discuss the one aspect of pre-planning that appeared to influence full implementation of the CAST program by the school teaching staff: commitment or engagement in the change process. As previously mentioned, full commitment from the in-school co-facilitator was evident at all schools. It was a full commitment and engagement from individual teachers in more than half of the schools that was lacking. Teachers variously reported feeling "left out of the loop”, or were unclear about what was expected of them. This appeared to be due to some teachers' sceptical view of the program. When asked about their initial expectations of the program, some teachers commented that they thought it would be just the latest in a series of initiatives, or that long term results were unlikely with such a short term intervention.

Lack of teacher engagement was also due to communication issues within the schools. 
The CAST program appeared to enjoy more success at schools where all staff felt involved due to open and regular communication. There appeared to be three points in the implementation process where there was potential for communication to break down. First, the initial meeting between CAST and school principal is crucial in outlining the requirements of the school, as is ensuring that notification of these requirements is passed on to all school staff. Once a program is chosen for implementation, all personnel should be aware of the program and how it will work, and should be committed to carrying out the program (Greenberg et al., 2005).

Second, it was evident that effective communication needed to be established between the CAST clinician and the co-facilitator, particularly in defining their respective roles. This relationship can impact heavily on the quality of implementation, as trainers need to be adequately prepared and experienced to provide the technical support and basic encouragement required by those implementing the program in schools (Greenberg et al., 2005). Some co-facilitators reported that they were initially uncertain of their role in the children's groups, especially in terms of discipline. These groups were made up of children normally separated in classrooms due to their challenging behaviours, and as a consequence they were difficult to control at times, and according to some school personnel, the CAST clinician’s “lack of teaching skills” increased the challenge of these groups. Co-facilitators reported being unsure if they were able to discipline the group or whether this was the role of the CAST worker, or indeed whether the program required that the children be disciplined at all. This issue demonstrates the importance of the school staffs' understanding of the program. CAST children's groups are therapeutic rather than teaching groups. Scenarios are deliberately orchestrated in the groups to encourage children to learn and practise new skills to deal more effectively with frustrating situations. It seems that the co-facilitators were initially unaware of this aspect of the group-work. It should be said, however, that this issue was generally resolved within the first one or two group sessions. 
The third important area of communication occurs in the relationship between the co-facilitator and the junior teachers, and how well the co-facilitator's role, and the expectations of the teachers are communicated. The impression from the majority of teachers interviewed was that they were expecting the CAST clinicians to report directly to them about their students. Han and Weiss (2005) found that feedback from the external agency delivering training and support to the school is critical in enhancing teachers' implementation skills and promoting their motivation to implement the program. In contrast, with the CAST program, feedback to teachers is generally seen as part of the role of the co-facilitator. The co-facilitator is required to discuss with the CAST clinician outcomes after each session, and then pass on to the teachers a summary of what has happened in the session, what is expected in the classroom for the week, and pass on any specific information about particular students. In many cases teachers reported that this communication did not occur. This issue leads to consideration of the implementation support system, and where it did not deliver as planned.

While the majority of school staff reported that the CAST clinicians were supportive, and able to give advice when asked, they also suggested that teachers often felt uninvolved in the program. It was common for teachers to have no knowledge of how parent groups were run, which parents were attending, or what actually happened in the children’s groups. Teachers suggested meeting more regularly with CAST clinicians and parents to address their perceived lack of involvement. This has the potential to improve the effectiveness of the program, increasing teacher involvement, reinforcing the holistic approach, and enabling teachers to enter into more of a partnership with parents, under the guidance of the CAST clinician. Meetings of this type may have the potential to increase consistency and awareness. It would also create an opportunity for the teachers to receive much requested feedback. Research has found that teaching staff require adequate preparation, in terms of training that is of sufficient intensity (Han \& Weiss, 2005), and the ongoing support of guidance and counselling personnel, including feedback on performance. 
Various studies have indicated that performance feedback by an external consultant can increase teachers' use of the intervention, and improve treatment fidelity (Jones, Wickstrom, \& Friman, 1997; Noell, Witt, Gilbertson, Ranier \& Freeland, 1997). Feedback empowers the in-school implementers to run and adapt the program, while still adhering to core program principles, when they are no longer receiving intensive consultation and assistance. Based on the interview data, CAST clinicians delivered sufficient feedback to the co-facilitators, who all expressed confidence in continuing to run the program in their school. However, the issue of ongoing support to sustain the program was a concern for most schools. It is evident that the schools do not want a "quick fix and leave"; they are interested in maintaining the collaborative effort of running the program with some form of external support. The amount of support required by each school will depend on the success of the initial supported implementation phase. Specifically, whether the in-school implementers are sufficiently committed to the program, and sufficiently trained and supported, so that their motivation to continue the implementation becomes self-sustaining.

\section{Conclusion}

The conceptual model developed by Greenberg and colleagues appears to be a robust and useful framework to utilise in examining the implementation of the CAST model, despite the fact that aspects of the program continued to evolve during the first phase of implementation in Victorian schools. As far as we can ascertain this is the first evaluation to use the model as a framework in evaluating a school-based program in Australia, and it appears to be generally transferable from the United States to the Australian context. Although the availability and funding of schoolbased preventative programs is comparatively more limited in Australia, the same implementation issues appear to apply in the local context. The model allowed close examination of how the CAST program was implemented within naturally occurring constraints, and what key factors and issues in the school setting affected the quality of program implementation. 
Using the model as a framework allowed us to conclude that the vast majority of elements of the CAST program were well implemented in the sixteen schools involved in the pilot study.

The implementation of any program does not occur in a vacuum, a broad array of factors outside the program may affect the program implementation and its outcomes, particularly when a program model is relying upon effective collaboration between various agencies. Greenberg and colleagues (2005) elaborate on some of these factors, including external factors at the classroom level (implementer characteristics and behaviour; classroom climate; and peer relations), the school level (logistical and administrative support), the district level (attitudes of school administrators, school boards, and parents) and at the community level (relationship with community services and agencies). While some of these factors were addressed in this current evaluation, for example factors at the school level, other factors are beyond the scope of this current project. It is imperative to consider the impact of these external factors when any project "goes to scale”. Considering CAST is currently being rolled out across Victoria, the impact of these factors on quality implementation, and scaling up, should be closely examined in a statewide evaluation of the CAST program.

One limitation of Greenberg and colleagues’ (2005) framework for evaluation is that it does not sufficiently attend to the partnerships that underpin successful implementation of school-based preventive programs. In identifying the contextual factors that affect program delivery and effectiveness, Greenberg et al. do acknowledge the importance of, for example, gaining support from the school principal, ensuring positive school-family relations, and delivering training for teachers in a collaborative style. However, this falls short of conceptualising partnership as an integral element of the evaluation framework. There are now robust empirical findings attesting to the importance of such partnerships. For instance, a systematic review of school-based mental health services identified that an important feature of successful programs was multi-level 
targeting that involved parents, teachers and peers. These interventions included teacher education in management of the classroom, parent training in child management, and cognitivesocial skills training in the children themselves (Rones and Hoagwood, 2000). Best practices in school-based prevention programs require that programs are planned, developed and evaluated collaboratively between parents and the school (Shepard and Carlson, 2003). Effective schoolparent communication, and teaching parents how to construct a home environment that promotes positive behaviours, have been critical to the success of the Linking the Interests of Families and Teachers program (Reid, Eddy, Fetrow and Stoolmiller, 1999; Eddy, Reid and Fetrow, 2000). The Positive Behaviour Support program (Minke and Anderson, 2005), the School and Family Intervention Model (Bemak and Cornely, 2002) and health promoting school initiatives (Deschesnes, Martin and Hill, 2003) also depend upon effective family-school collaboration at all levels of program implementation. While there is little consensus about how to cultivate partnerships, Christenson (2004) has articulated an approach which draws on the principles of systems-ecological theory and explicates the process for partnering with families.

Our evaluation of the CAST program revealed that Greenberg and colleagues' (2005) model needs to be supplemented: because collaborative relationships are foundational - not incidental or secondary - to the conceptualisation of the CAST program, the evaluation framework itself must be revised and expanded to include this element.

Greenberg's model highlights the myriad of interrelated factors, present in school settings, which may become barriers to effective implementation of school-based programs. There is a clear need to further increase researchers' and program developers' awareness of these factors, and to develop a means of measuring them, so that relationships between quality of implementation and both short- and long-term program outcomes can be empirically evaluated. This information would be invaluable in helping determine which elements of an intervention and the associated 
support system must be maintained and nurtured by the collaborating parties, and which factors at a school level are potential barriers to effective implementation. Developments in this direction would assist in ensuring quality outcomes for school-based interventions in the future.

\section{Acknowledgements}

We acknowledge Dr. Louise Hayes (former Team Leader of the CAST Project and lecturer at the University of Ballarat) and two anonymous reviewers for their valuable comments on an earlier draft of this paper. 


\section{References}

Bemak, F. and Cornely, L. (2002) The SAFI Model as a critical link between marginalized families and schools: A literature review and strategies for counsellors. Journal of Counselling and Development, 80, 322-331.

Bierman, K.L., Coie, J.D., Dodge, K.A., Foster, E.M., Greenberg, M.T., Lochman, J.E., et al. (2004). The effects of the fast track program on serious problem outcomes at the end of elementary school. Journal of Clinical Child \& Adolescent Psychology, 33 (4), 650-61.

Christenson, S. (2004) The family-school partnership: An opportunity to promote the learning competencies of all students. School Psychology Review, 33(1), 83-104.

Clark, L., \& Elliot, S.N. (1988). The influence of treatment strength information on knowledgeable teachers' pre-treatment evaluations of social skills training methods. Professional School Psychology, 3, 241-251.

Collaborative for Academic, Social, and Emotional Learning (CASEL) (2003). Safe and sound: An educational leaders' guide to evidence-based social and emotional learning (SEL) programs. http://www.casel.org (accessed October 16, 2006).

Conduct Problems Prevention Research Group. (1992). A developmental and clinical model for the prevention of conduct disorder: The FAST Track Program. Development and Psychopathology, 4, 509-527. 
Deschesnes, M., Martin, C. and Hill, A. (2003) Comprehensive approaches to school health promotion: how to achieve broader implementation? Health Promotion International, 18 (4), 387-396.

Domitrovich, C.E., \& Greenberg, M.T. (2000). The study of implementation: current findings from effective programs that prevent mental disorders in school-aged children. Journal of Educational and Psychological Consultation, 11, 193-221.

Eddy, J., Reid, J., \& Fetrow, R. (2000). An elementary school-based prevention program targeting modifiable antecedents of youth delinquency and violence: Linking the Interests of Families and Teachers (LIFT). Journal of Emotional \& Behavioral Disorders, 8(3), 165-177.

Elias, M.J., Zins, J.E., Graczyck, P.A., \& Weissberg, R.P. (2003). Implementation, sustainability, and scaling up of social-emotional and academic innovations in public schools. School Psychology Review, 32, 303-319.

Fullan, M., Miles, M.B., \& Taylor, G. (1980). Organisational development in schools: The state of the art. Review of Educational Research, 50, 121-183.

Greenberg, M.T., Domitrovich, C.E., \& Bumbarger, B. (2001). The prevention of mental disorders in school-aged children: Current state of the field. Prevention and Treatment, 4, Article 1.

http://journals.apa.org/prevention/volume4/pre0040001a.htm 
Greenberg, M.T., Domitrovich, C.E., Graczyk, P.A., \& Zins, J.E. (2005). The Study of Implementation in School-based Preventative Interventions: Theory, Research, and Practice (Volume 3). DHHS. Rockville, MD: Center for Mental Health Services, Substance Abuse and Mental Health Services Administration.

Han, S.S., \& Weiss, B. (2005). Sustainability of teacher implementation of schoolbased mental health programs. Journal of Abnormal Child Psychology, 33 (6), 665-679.

Hill, J. (2002). Biological, psychological and social processes in the conduct disorders. Journal of Child Psychology and Psychiatry, 43, 133-164.

Jones, K.M., Wickstrom, K.F., \& Friman, P.C. (1997). The effects of observational feedback on treatment integrity in school-based behavioural consultation. School Psychology Quarterly, 12, 316-326.

Kam, C., Greenberg, M.T., \& Walls, C.T. (2003). Examining the role of implementation quality in school-based prevention using the PATHS curriculum. Prevention Science, 4, 55-63.

Kealey, K.A., Perterson, A.V., Jnr., Gaul, M.A., \& Dinh, K.T. (2000). Teacher training as a behaviour change process: Principles and results from a longitudinal study. Health Education and Behavior, 27, 64-81.

Minke, K. and Anderson, K. (2005) Family-School collaboration and positive behaviour support. Journal of Positive Behaviour Interventions, 7(3), 181-185. 
Noell, G.H., Witt, J.C., Gilbertson, D.N., Ranier, D.D., \& Freeland, J.T. (1997).

Increasing teacher intervention implementation in general education settings through consultation and performance feedback. School Psychology Quarterly, 12, 77-88.

Reid, J., Eddy, J., Fetrow, R., and Stoolmiller, M. (1999) Description and immediate impacts of a preventive intervention for conduct problems. American Journal of Community Psychology, 27(4), 483-517.

Reimers, T.M., Wacker, D.P., \& Koeppl, G. (1990). Acceptability of behavioural interventions: A review of the literature. School Psychology Review, 16(2), 212-227.

Rones, M. and Hoagwood, K. (2000) School-based mental health services: A research review. Clinical Child and Family Psychology Review, 3(4), 223-241.

Sanders, M. R. (1999). Triple P-Positive Parenting Program: Towards an empirically validated multilevel parenting and family support strategy for the prevention of behavior and emotional problems in children. Clinical Child and Family Psychology Review, 2(2), 71-82.

Sawyer, M.G., Arney, F.M., Baghurst, P.A., Clark, J.J., Graetz, B.W., Kosky, R.J., et al. (2001). Mental Health of Young People in Australia: Key findings from the child and adolescent component of the national survey of mental health and well being. Australian and New Zealand Journal of Psychiatry, 35, 806-814.

Scott-Skillman, T. (1992). Student services and special programs: A report on program effectiveness. Board of Governors, California Community Colleges, Sacramento. http://eric.ed.gov/ERICDocs/data/ericdocs2/content_storage_01/0000000b/80/23/4e/a2.pdf 
Shepard, J. and Carlson, J. (2003) An empirical evaluation of school-based prevention programs that involve parents. Psychology in the Schools, 40(6), 641-656.

Spoth, R., Goldberg, C., \& Redmond, C. (1999). Engaging families in longitudinal preventive intervention research: Discrete time survival analysis of socioeconomic and social emotional risk factors. Journal of Consulting and Clinical Psychology, 67, 157-163.

Stormshak, E.A., Kaminski, R., \& Goodman, M.R. (2002). Enhancing the parenting skills of Head Start families during the transition to kindergarten. Prevention Science, 3, 223234.

Stormshak, E.A., Dishion, T.J., Light, J., \& Yasui, M. (2005). Implementing familycentred intervention within the public middle school: Linking service delivery to change in student problem behaviour. Journal of Abnormal Child Psychology, 33 (6), 723-733.

Stufflebeam, D.L. (2000). The CIPP model for evaluation. In D.L. Stufflebeam, G. F. Madaus, \& T. Kellaghan, (Eds.), Evaluation models (2 ${ }^{\text {nd }}$ ed.). (Chapter 16). Boston: Kluwer Academic Publishers.

Sutherland, D., \& Sokal, L. (2003). Resiliency and capacity building in inner-city learning communities. Winnipeg, MB: Portage \& Main Press. 